\title{
HUMAN IMMUNE RESPONSE TO SAND FLY SALIVARY GLAND ANTIGENS: A USEFUL EPIDEMIOLOGICAL MARKER?
}

\author{
ALDINA BARRAL, EDUARDO HONDA, ARLENE CALDAS, JACKSON COSTA, VERA VINHAS, EDGAR D. ROWTON, \\ JESUS G. VALENZUELA, ROSANE CHARLAB, MANOEL BARRAL-NETTO, AND JOSÉ M.C. RIBEIRO \\ Centro de Pesquisas Gonçalo Moniz (FIOCRUZ), Salvador, Bahia, Brazil; Serviço de Imunologia, Hospital Universitário \\ Professor Edgard Santos, Universidade Federal da Bahia, Salvador, Bahia, Brazil; Departamento de Patologia, Universidade \\ Federal do Maranhão, São Luiz, Maranhão, Brazil; Department of Entomology, Walter Reed Army Institute of Research, \\ Washington, District of Columbia; Section of Medical Entomology, Laboratory of Parasitic Diseases, National Institutes of \\ Allergy and Infectious Diseases, Bethesda, Maryland
}

\begin{abstract}
Antibody ( $\operatorname{IgG}$ ) responses to salivary gland homogenate and to a recombinant salivary protein from the sand fly Lutzomyia longipalpis were investigated using sera from children living in an endemic area of visceral leishmaniasis in Brazil. We classified children into four groups according to their responses to Leishmania antigen: (Group I) positive serology and positive delayed type hypersensitivity (DTH), (Group II) positive serology and negative DTH, (Group III) negative serology and positive DTH, and (Group IV) negative serology and negative DTH. A highly significant correlation was found between anti-salivary gland IgG levels and DTH responses. An L. longipalpis salivary recombinant protein used as an antigen in an enzyme-linked immuno sorbent assay (ELISA) gave a significant but different result. A positive correlation was found between anti-Leishmania IgG and anti-recombinant protein IgG titers. The results indicate that sand fly salivary proteins may be of relevance to the study the epidemiology of leishmaniasis.
\end{abstract}

\section{INTRODUCTION}

The leishmaniases are a group of mostly zoonotic diseases caused by protozoan parasites of the genus Leishmania which are transmitted by phlebotomine sand fly vectors. Sand flies acquire the parasite, which lives as intracellular amastigotes in their vertebrate hosts, while taking a blood meal. The parasites develop from amastigotes to extracellular promastigotes in the sand fly gut, multiply, and transform to infective metacyclics that accumulate in the anterior portion of the fly's digestive canal. Once infective protozoa invade their vector's mouthparts, they can be transmitted to another vertebrate when the fly attempts to take another blood meal. ${ }^{1}$

Visceral American leishmaniasis (VL) caused by Leishmania chagasi is endemic in several areas in Brazil. Within these regions, most of the infections are subclinical with leishmanin-positive patients normal upon physical examination. ${ }^{2}$ Full-blown VL is characterized by unimpeded parasite multiplication in bone marrow, liver, and spleen, leading to severe weight loss, hepatosplenomegaly, anemia, leukopenia, and thrombocytopenia. Development of clinical disease is possibly related to nutrition status ${ }^{3}$ and young age ${ }^{4}$ among other factors. A strong delayed type hypersensitivity (DTH) to leishmanial antigen (leishmanin) is normally associated with resistance to manifestations of the disease. ${ }^{5}$ Additionally, laboratory experiments indicate that immunity to sand fly vector salivary antigens may also confer protection. ${ }^{6-9}$

While taking a blood meal, sand flies salivate on their hosts. The saliva of blood-sucking animals contains a repertoire of molecules that modulate their host's hemostatic, inflammatory, and immune responses. The New World sand fly Lutzomyia longipalpis has the peptide maxadilan as its salivary vasodilator. ${ }^{10,11}$ Maxadilan also has immunosuppressive properties ${ }^{12}$ and the anti-clotting molecule of Lutzomyia has been purified and cloned. ${ }^{13}$ Additionally, several salivary gland cDNAs from Lutzomyia longipalpis have been recently cloned, including the salivary apyrase and hyaluron- idase $^{13}$ Salivary components may also play a role in helping the establishment of pathogens in their vertebrate hosts. ${ }^{6}$ Tick saliva has been implicated in the successful transmission of several tick-borne viruse ${ }^{14,15}$ and saliva of both Lutzomyia longipalpis and Phlebotomus papatasi has been implicated in enhancing transmission of Leishmania major parasites in mouse models of this disease. ${ }^{7,8}$ Conversely, host immunity to vector saliva may decrease infectivity of the transmitted pathogens..$^{9,16}$

A large body of work demonstrates the production by humans and other vertebrates of antibodies against the salivary gland components of blood-sucking insects and ticks. ${ }^{17-19} \mathrm{Al}-$ though most of this work is aimed at preventing and treating undesirable allergic responses, or developing anti-arthropod vaccines, these responses may also be used as epidemiological markers of vector exposure, such as to Ixodes scapular$i s$, a vector of Lyme disease. ${ }^{20,21}$ In the case of leishmaniasis, there is a dual interest in understanding the nature of the human response to sand fly salivary antigens. 1) Sand fly populations tend to be clustered (Miranda and others, unpublished data). Screening of human antibodies to sand fly saliva could be a useful indicator the spatial distribution of sand flies in a particular region, thus helping to direct vector and disease control efforts. 2) Immunity to sand fly salivary antigens may decrease expression of leishmaniasis or disease severity ${ }^{6,9}$ Accordingly, the purpose of this work was to investigate whether sera from children living in an area endemic for visceral leishmaniasis were able to differentially recognize salivary gland antigens of the vector sand fly depending on the children's exposure to Leishmania as determined by their cellular (measured by cutaneous DTH) and humoral IgG responses to Leishmania antigens. The results indicate that anti-sand fly antibody studies can be used within the context of the epidemiology of leishmaniasis.

\section{MATERIALS AND METHODS}

Sand flies. Sand flies were reared at the Walter Reed Army Medical Research Institute on a fermented mixture of 
rabbit chow and rabbit feces as described previously. ${ }^{22}$ Adult sand flies had with free access to a $10 \%$ solution of sucrose unless otherwise specified. Salivary glands from 3-to 10day-old adult female flies were dissected and transferred to 10 or $20 \mu \mathrm{L}$ Hepes $10 \mathrm{mM} \mathrm{pH} 7.0, \mathrm{NaCl} 0.15 \mathrm{M}$ in $1.5 \mathrm{~mL}$ polypropylene vials, usually in groups of 20 pairs of glands in $20 \mu \mathrm{L}$ of Hepes saline, or individually in $10 \mu \mathrm{L}$ of Hepes saline. Salivary glands were kept at $-75^{\circ} \mathrm{C}$ until needed, when they were disrupted by sonication using a Branson Sonifier 450 homogenizer (Branson, Danbury, CT). ${ }^{23}$ Salivary homogenates were centrifuged at $10,000 \mathrm{~g} \times 2 \mathrm{~min}$; the supernatants were used for the experiments.

Preparation of recombinant antigen. The recombinant antigen used in this work refers to the salivary anti-clotting protein characterized in a previous publication. ${ }^{13}$ The GenBank accession number for the cDNA sequence is AF131932. A plasmid containing the Lutzomyia longipalpis anticoagulant sequence was used as a template to amplify only the sequence coding for the processed protein. Accordingly, we used CTA CAA GTT ACT GAG AAG GAA CTT as a sense primer and CTT TTC TTG ACA TAC AAA ATG ATG as an antisense primer. Polymerase chain reaction (PCR) conditions were as follows: 1 cycle of $3 \mathrm{~min}$ at $94^{\circ} \mathrm{C}$, 25 cycles of $1 \mathrm{~min}$ at $94^{\circ} \mathrm{C}, 30 \mathrm{sec}$ at $45^{\circ} \mathrm{C}, 30 \mathrm{sec}$ at $72^{\circ} \mathrm{C}$, and a final cycle of $10 \mathrm{~min}$ at $72^{\circ} \mathrm{C}$. Amplification of a single product was confirmed in a $1.5 \%$ agarose gel. The obtained PCR product was immediately ligated to pTrcHis2-TOPO TA expression vector (Invitrogen, San Diego, CA) following the manufacturer's protocol.

Cell transformation. Cells were transformed with the ligation mixture, plated in LB-agar-ampicillin $(100 \mu \mathrm{g} / \mathrm{mL})$ plates and incubated overnight at $37^{\circ} \mathrm{C}$. Isolated colonies were picked and transferred to $5 \mathrm{~mL}$ of LB-ampicillin (100 $\mu \mathrm{g} / \mathrm{mL}$ ). The cultures were grown at $37^{\circ} \mathrm{C}$ for 6 hours and stored at $4^{\circ} \mathrm{C}$ until PCR analysis. Five $\mu \mathrm{L}$ of the cultures were used as a template for a PCR reaction used to determine the presence of the anti-coagulant insert. We utilized the same sense and antisense primers described above and the following PCR conditions: 1 cycle of $5 \mathrm{~min}$ at $75^{\circ} \mathrm{C}, 1$ cycle of $4 \mathrm{~min}$ at $94^{\circ} \mathrm{C}, 35$ cycles of $30 \mathrm{sec}$ at $94^{\circ} \mathrm{C}, 30 \mathrm{sec}$ at $40^{\circ} \mathrm{C}$, and $45 \mathrm{sec}$ at $72^{\circ} \mathrm{C}$. Amplification of a PCR product of about 420 base pairs (bp) suggested the presence of the insert. Colonies containing the insert were regrown and their plasmids extracted and sequenced in both directions to confirm the presence of the anti-coagulant and the orientation of the sequence.

Expression of recombinant anticoagulant. A $500 \mathrm{~mL}$ cell culture containing the anticoagulant expression vector was grown in LB-ampicillin $(100 \mu \mathrm{g} / \mathrm{mL})$ at $37^{\circ} \mathrm{C}$, shaking at $300 \mathrm{rpm}$, until it reached 1 unit O.D. (600 nm). Isopropyl thiogalactoside $(1 \mathrm{mM})$ was added to the culture and incubated for 6 hours at $37^{\circ} \mathrm{C}$. Expression of the recombinant protein was confirmed by SDS-PAGE ( $4-20 \%$ gel). The control sample was a cell culture with the pTrcHis2-TOPO vector alone. Cells were harvested by spinning for $20 \mathrm{~min}$ at $1,500 \times g\left(4^{\circ} \mathrm{C}\right)$. The pellet was resuspended in Tris- $\mathrm{HCl} \mathrm{pH}$ 7.4, $20 \mathrm{mM}$ EDTA, and lysozyme $(8 \mathrm{mg} / \mathrm{mL})$ was added to the culture. The culture was left at room temperature for one hour with intermittent shaking. Sodium chloride $(0.5 \mathrm{M}$ final concentration) and triton X-100 (2.5\% final) were added and the sample was incubated at room temperature for $30 \mathrm{~min}$ with shaking. The culture was then spun at $10,000 \times \mathrm{g}$ for $50 \mathrm{~min}\left(4^{\circ} \mathrm{C}\right)$. The pellet was resuspended with Tris-EDTA$1 \%$ triton solution and the mixture sonicated three times for $30 \mathrm{sec}$ then cooled for $1 \mathrm{~min}$ on ice. The cells were centrifuged again and the entire procedure repeated five times with washes of the pellet using Tris-EDTA buffer. The pellet was then stored at $-75^{\circ} \mathrm{C}$ until use. The pellet was solubilized in GuHCl $6 \mathrm{M}$, Tris-HCl $\mathrm{pH}$ 8.0, EDTA $2 \mathrm{mM}$ and sonicated three times for $30 \mathrm{sec}$ with 1 minute cooling on ice. After sonication, the solution was incubated for two hours at room temperature and then centrifuged at $25,000 \times g$ for $30 \mathrm{~min}$ at $4^{\circ} \mathrm{C}$. The supernatant was recovered, DTE was added for a final concentration of $65 \mathrm{mM}$, and it was incubated at room temperature for 2 hours. The solution was then added to a refolding buffer (Tris- $\mathrm{HCl} 0.1 \mathrm{M} \mathrm{pH}$ 8.0, L-arginine-HCl 0.5 M, GSSG $0.9 \mathrm{mM}$, and EDTA $2 \mathrm{mM}$ ), and the mixture was incubated for 36 hours at $4^{\circ} \mathrm{C}$, then dialyzed against Tris $\mathrm{HCl} 20 \mathrm{mM} \mathrm{pH}$ 7.4. After dialysis, the recombinant protein was purified by reverse phase HPLC using a 60 min gradient of $10-60 \%$ acetonitrile with trifluoroacetic acid $0.1 \%$, at 2 $\mathrm{mL} / \mathrm{min}$ using a $1 \mathrm{~cm} \times 25 \mathrm{~cm}$ octadecyl-silica column model 218TP510 (Vydac, Hesperia, CA). Absorbance at $280 \mathrm{~nm}$ was monitored. Fractions of the main peak were pooled, and analyzed by reducing SDS-PAGE, mass spectrometry, and Edman degradation. The pooled fractions were homogeneous and yielded the expected amino-terminal sequence ALLQVTVKELSDGKKIFISK, with the two first amino acids being from the vector.

Anti-insect antigen serology by ELISA. ELISA plates were coated with 5 pairs of salivary glands/mL (approximately $5 \mu \mathrm{g}$ protein $/ \mathrm{mL}$ ), or with $1 \mu \mathrm{g}$ recombinant protein/ $\mathrm{mL}$ in carbonate buffer $\left(\mathrm{NaHCO}_{3} 0.45 \mathrm{M}, \mathrm{Na}_{2} \mathrm{CO}_{3} 0.02 \mathrm{M}\right.$, $\mathrm{pH}$ 9.6) overnight at $4^{\circ} \mathrm{C}$. After three washes with PBS$0.05 \%$ Tween, the plates were blocked for 1 hour at $37^{\circ} \mathrm{C}$ with PBS- $0.1 \%$ Tween plus $0.05 \%$ BSA. Sera were diluted 1:100 with PBS-0.05\% Tween and incubated overnight at $4^{\circ} \mathrm{C}$. After further washings, the wells were incubated with alkaline-phosphatase-conjugated anti-human IgG (Sigma, St. Louis, MO) at a $1: 1,000$ dilution for 45 minutes at $37^{\circ} \mathrm{C}$. Following another washing cycle, the color was developed for 30 minutes with a chromogenic solution of p-nitrophenylphosphate in sodium carbonate buffer $\mathrm{pH} 9.6$ with $1 \mathrm{mg} /$ $\mathrm{mL}$ of $\mathrm{MgCl}_{2}$.

Preparation of Western blots. For Western blots, we used 16\% Tris-Glycine, $1.0 \mathrm{~mm}$ thick gels, running with sodium dodecyl sulfate (Novex, San Diego, CA). The gel type, recommended for 2D gels, has one small side well for prestained molecular weight markers (myosin, bovine serum albumin, glutamic dehydrogenase, alcohol dehydrogenase, carbonic anhydrase, myoglobin, lysozyme, aprotinin, and insulin, chain B, obtained from Novex) and a large single well, to which were added the contents of 40 pairs of salivary glands (approximately $40 \mu \mathrm{g}$ of protein) treated with $8 \%$ SDS and 4\% 2-mercaptoethanol in Tris- $\mathrm{HCl}$ buffer $0.5 \mathrm{M}$ $\mathrm{pH} 6.8,10 \%$ glycerol, and $1 \%$ bromophenol blue dye, and heated for $5 \mathrm{~min}$ at $100^{\circ} \mathrm{C}$. The gel was developed with TrisGlycine buffer according to the manufacturer's instructions and transferred to nitrocellulose using a Blot-Module for the XCell II Mini-Cell (Novex). After transfer, free sites were blocked with PBS-0.05\% Tween plus $0.5 \%$ non-fat dried milk for two hours at $37^{\circ} \mathrm{C}$. The strips were washed with 
PBS- $0.05 \%$ Tween and incubated with sera (diluted 1:100 in PBS- $0.05 \%$ Tween and $0.5 \%$ nonfat dried milk) overnight at $4^{\circ} \mathrm{C}$. Following further washings, strips were incubated with rabbit alkaline-phosphatase-conjugated anti-human IgG for 1 hour at $37^{\circ} \mathrm{C}$. Blots were then washed and developed with nitro blue tetrazolium and 5-bromo-4-chloro-3-indolyl phosphate.

Anti-Leishmania serology by ELISA. Leishmania were cultivated in Schneider's medium, and the organisms disrupted by freeze-thaw cycles and then centrifuged at 40,000 $\mathrm{g}$ for 20 minutes. Protein content of the supernatant was determined by Lowry's method. Samples were stored at $-20^{\circ} \mathrm{C}$ until used. The test was performed as previously described, ${ }^{24}$ and has been documented to yield specific (98\%) and sensitive $(99 \%)$ responses in serological tests. The spectrophotometric absorbance values (OD) of 1/100 dilution of normal sera samples (mean $+3 \mathrm{SD}$ ) were used as the cutoff for a positive response.

Delayed-type hypersensitivity test. Delayed-type hypersensitivity (DTH) tests were performed as previously described. ${ }^{25}$ Briefly, cutaneous DTH was assessed by intradermally inoculating patients with $L$. chagasi protein. Induration was measured after 48 hours. A positive test was defined as induration greater than $5 \mathrm{~mm}$ at maximum width.

Study population. Sera used in the present study were obtained from an epidemiological survey of visceral leishmaniasis in an endemic region of São Luiz, capital of Maranhão State. During the prospective study, anti-Leishmania DTH and serology were performed twice a year in children whose age was less than 7 years during 1996-1997. Sera from individuals with visceral leishmaniasis or those who were positive either by serology or DTH in the first survey were not used in the present report. A visceral leishmaniasis case was defined by the following criteria: fever, weight loss, hepatosplenomegaly, and anemia. Positivity in the anti-leishmanial tests reported here indicates a recent conversion determined by a sensitive and specific ELISA and/or by DTH. Thus, none of the individuals in the data set had disease, and all had had negative responses to leishmanial antigen during the preceding six-month period. Accordingly, antiLeishmania-reacting children were presumably exposed recently to the pathogen. Assuming that recent seroconversion represents infection and a positive DTH is a marker of protection against leishmaniasis in subclinical cases, ${ }^{5}$ we classified children into four groups: (Group I) positive serology and positive DTH, (Group II) positive serology and negative DTH, (Group III) negative serology and positive DTH, and (Group IV) negative serology and negative DTH. Informed consent was obtained from parents or legal guardians of minors. The project was approved by an appropriate institutional review board from the Osvaldo Cruz Foundation.

Statistical analysis. The data obtained in this work was not normally distributed, even after several attempts at transformation. Accordingly, the Kruskal-Wallis Analysis of Variance on Ranks (KW-ANOVA) was used to evaluate significance among group medians. The Kolgorovov-Smirnov test was used to test for a normally distributed population. Dunn's procedure was used to perform pairwise multiple comparisons. Correlation tests were done with the Spearman rank order test. A $P$-value $<0.05$ was used to establish the significance level. A $P<0.01$ is indicated in the text to be

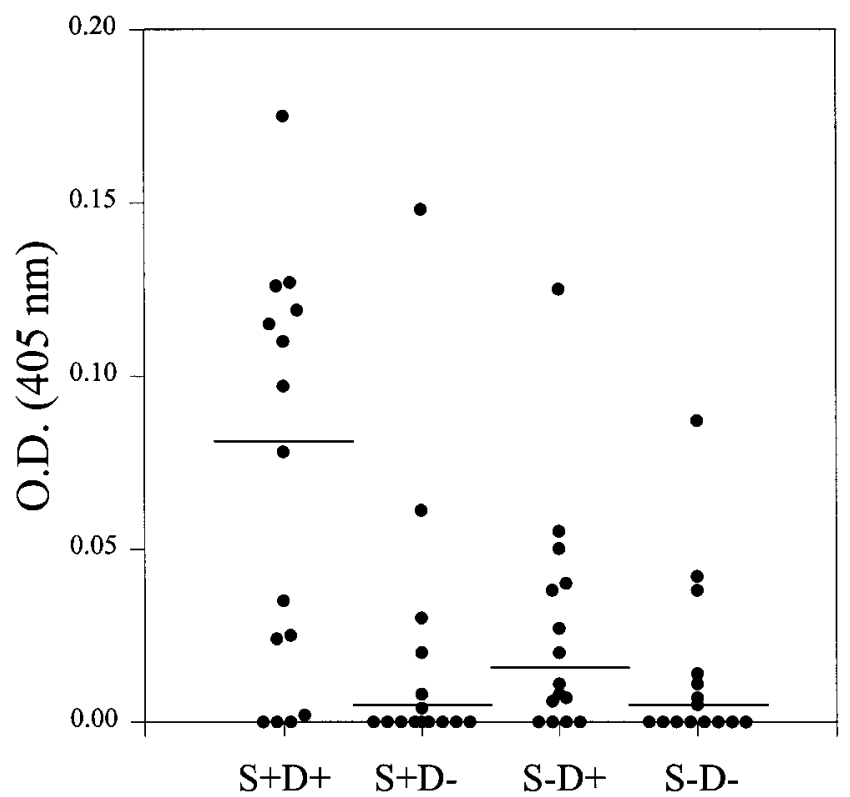

FIGURE 1. Human serum IgG response against salivary gland homogenate of the sand fly Lutzomyia longipalpis. Human sera were from individuals either positive $(\mathrm{D}+)$ or not $(\mathrm{D}-)$ to a leishmanin skin test, or having $(\mathrm{S}+)$ or not $(\mathrm{S}-)$ high $\mathrm{IgG}$ serum titer against Leishmania as detected by enzyme-linked immunosorbent assay (ELISA). The ordinate represents the absorbance of the ELISA reaction of these sera against sand fly salivary homogenate. The symbols indicate results from 15 sera from each of the 4 groups used, and the lines represent their median values.

highly significant. Sigmastat version 2.0 (Jandel Scientific, San Raphael, CA) was used to perform the statistical tests.

\section{RESULTS}

To investigate whether a human population from an endemic area of visceral leishmaniasis had IgG antibodies against salivary gland antigens of the vector sand fly Lutzomyia longipalpis, we measured by ELISA the antibody level in sera of 60 children, which were stratified into four groups according to their reaction to both the DTH reaction $(\mathrm{D}+$ or $\mathrm{D}-$ ) and antibody level $(\mathrm{S}+$ or $\mathrm{S}-$ ) (Figure 1$)$. The KW-ANOVA test indicated that the group medians were significantly different $(P=0.001)$. Dunn's pairwise multiple comparison procedure indicated that the significant $(P<$ 0.05) comparisons were between the groups $\mathrm{S}+\mathrm{D}+$ and $\mathrm{S}+\mathrm{D}-$ and between $\mathrm{S}+\mathrm{D}+$ and $\mathrm{S}-\mathrm{D}-$.

Because the positive reaction described above could derive from nonspecific antibody responses, we measured the reactivity of the sera against salivary homogenates of the Old World sand fly, Phlebotomus papatasi (Figure 2). Although the optical densities of the ELISA tests were greater than when using L. longipalpis salivary homogenates, no significant differences were found among the medians of the four groups as tested by KW-ANOVA $(P=0.233)$.

Because large epidemiological investigations using salivary gland antigens are prohibitive due to the need for dissection of thousands of pairs of salivary glands, we tested the use of a recombinant salivary protein as an antigen for ELISA studies with 15 of the same sera in each group described above (Figure 3). The KW-ANOVA test indicated 


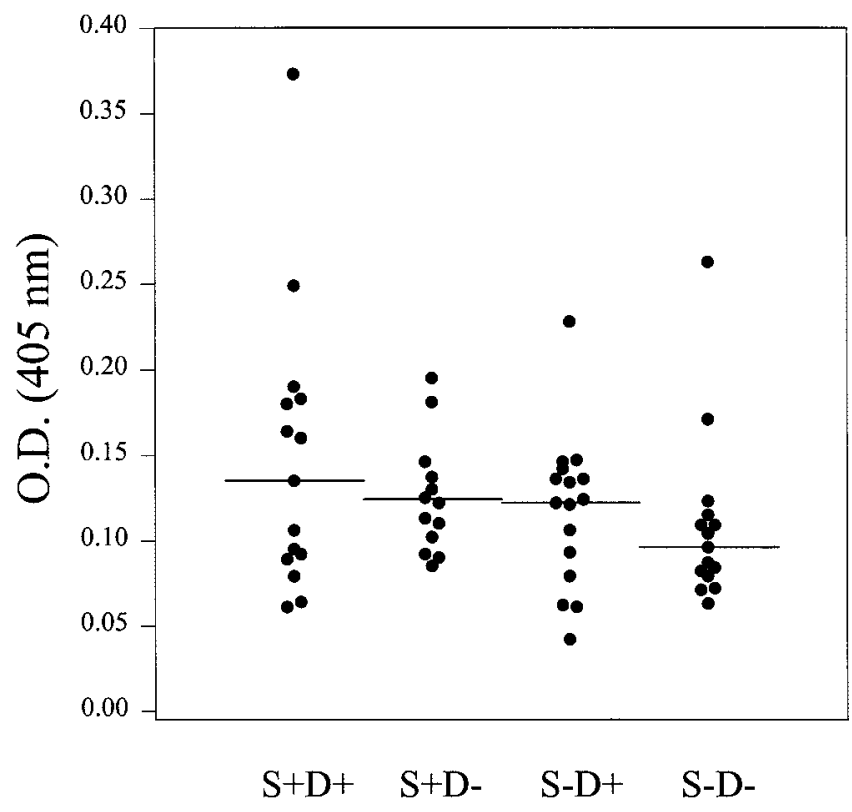

Figure 2. Human serum IgG response against salivary gland homogenate of the sand fly Phlebotomus papatasi. Fifteen sera in each class were used, except for the $\mathrm{S}+\mathrm{D}-$ group, where 14 sera only were used. Other conditions as in Figure 1.

the differences among the medians to be highly significant $(P<0.001)$. A pairwise multiple comparison test indicated that there were significant differences $(P<0.05)$ between groups $\mathrm{S}+\mathrm{D}-$ and $\mathrm{S}-\mathrm{D}-$ and groups $\mathrm{S}+\mathrm{D}-$ and $\mathrm{S}-\mathrm{D}+$.

To test whether the serologic response to the recombinant antigen correlated with that measured against whole salivary antigen as well as with the other two variables tested, namely, DTH induration and antibody to leishmanial antigen, we performed a Spearman rank order correlation test on these four variables by pooling the results reported in Figures 1 and 3. The results (Table 1) indicate that the response to the recombinant antigen correlates significantly with serological antibody response to leishmanial antigen $(P<0.001)$, and that anti-saliva antibody response correlates $(P=0.002)$ with DTH response to Leishmania. Unexpectedly, no correlation was found between responses to the recombinant antigen and whole salivary homogenate.

We evaluated by Western blots the complexity of the antigenic mixture in salivary gland homogenates of $L$. longipalpis using a selected sample of sera that tested either positive or negative by ELISA against L. longipalpis salivary homogenates. Sera with the 4 highest (thus designated positive) and 4 lowest (designated negative) OD readings in ELISA were tested in the blots. Results indicate that there are 6 main antigens, of which 3 are commonly recognized by sera from individuals with low response to Lutzomyia antigen. Antigens with molecular weights of approximately $6,12,36$, and $96 \mathrm{kDa}$ were recognized only by sera from individuals with serum IgG antibodies to Lutzomyia antigen (Figure 4).

\section{DISCUSSION}

Results presented in this paper indicate that children positive to leishmanin as assayed by a skin test react positively

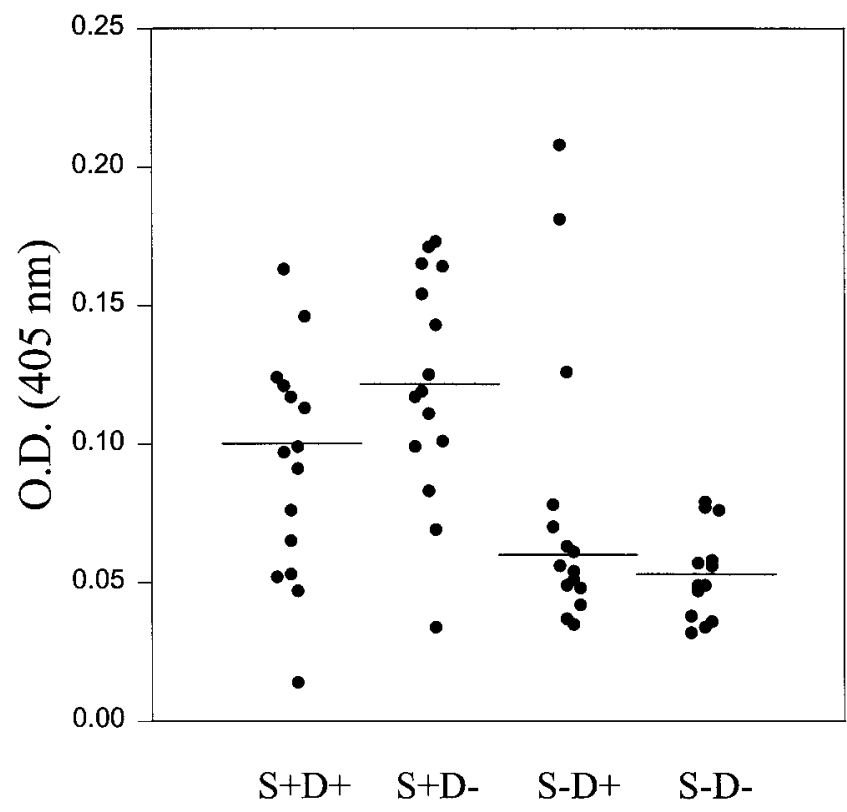

FIGURE 3. Human serum IgG response against recombinant salivary anti-clotting protein from the sand fly Lutzomyia longipalpis. Fifteen sera in each class are represented, except for the S-Dgroup where 13 sera were used. Other conditions as in Figure 1.

to salivary gland antigen of the sand fly L. longipalpis (Figure 1, Table 1). This serum IgG antisalivary homogenate response correlated positively with DTH intensity (Table 1). The complexity of the antigenic mixture comprised in the salivary gland homogenate is indicated by Western blots,

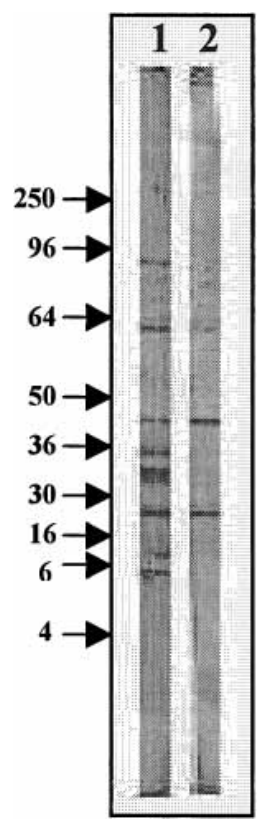

FIGURE 4. Western blots indicating human IgG serum reactivity against Lutzomyia longipalpis salivary gland antigens separated by SDS-polyacrylamide gel electrophoresis. $1=$ positive serum $2=$ negative serum. The results are representative of 4 positive and 4 negative sera, with the positive sera being the four most-reactive sera by enzyme-linked immuno sorbent assay against $L$. longipalpis salivary homogenate, and the negative sera being the four leastreactive sera. 
TABLE 1

Spearman rank order correlation test results for associations between antibody titers against recombinant salivary anti-clotting protein ( $\alpha$-rAC IgG), against sand fly salivary homogenate ( $\alpha$-saliva IgG), against Leishmania antigen ( $\alpha$-Leishmania $\mathrm{IgG})$, and by skin reaction to the leishmanin antigen (DTH)

\begin{tabular}{lccc}
\hline & $\begin{array}{c}\text { Delayed type } \\
\text { hypersensitivity }\end{array}$ & $\alpha$-saliva IgG & $\alpha$-Leishmania IgG \\
\hline$\alpha$-rAC IgG (n=59) & $\mathrm{r}=-0.0064$ & $\mathrm{r}=0.0512$ & $\mathrm{r}=0.450$ \\
& & & \\
DTH $(\mathrm{n}=60)$ & $P=0.616$ & $P=0.699$ & $P<0.001$ \\
& & $\mathrm{r}=0.394$ & $\mathrm{r}=0.0635$ \\
& $P=0.00197$ & $P=0.629$ \\
\hline $\mathrm{r}=$ correlation coefficient. & & & \\
$P=$ probability. & & &
\end{tabular}

where up to 6 bands were observed in some positive sera. These results have a two-fold implication: 1) individuals exposed to Leishmania recognize salivary gland antigens of the vector sand fly, a finding reported here for the first time and 2) to the extent that response to the vector salivary gland antigen is protective in the development of disease (a possibility substantiated in laboratory models of leishmaniasis), ${ }^{7-9,16}$ the possibility exists to track this cohort of children to investigate their disease outcome according to their antisalivary gland titer. This last implication, if proven negative (high anti-saliva titer negatively correlated with disease outcome), can give support for development of an anti-vectorbased vaccine for leishmaniasis.

Results indicate that individuals with low ELISA reactivity to Lutzomyia salivary antigens recognize 3 antigen bands by Western blots, but that up to 6 bands are recognized by sera from individuals having high antibody titers in the same ELISA test. The positive bands found in ELISA-negative individuals could be either the result of low exposure to the sand fly or due to cross-reactivity of some Lutzomyia antigens with other arthropod antigens. Indeed, antibody responses to the tick vector of Lyme's disease correlated with Borrelia burgdorferi antibody titer and also with ELISA titer against salivary gland homogenates of the non-vector tick Dermacentor variabilis, or even the mosquito Aedes aegypti. ${ }^{20}$ Use of a recombinant salivary protein from the tick Ixodes scapularis is now being used as a marker of exposure to the vector of Lyme disease, where antibody responses to the recombinant salivary calreticulin homologue correlate with the degree of engorgement of the tick on human. ${ }^{26,27}$

Serum IgG responses against Phlebotomus papatasi did not differ among the 4 groups tested (Figure 2). Although this result supports the conclusion that the response to $L$. longipalpis antigens is not an artifact due to nonspecific polyclonal IgG activation, it does not exclude the possibility of cross reactivity between antigens of L. longipalpis and $P$. papatasi, or, for that matter, any other arthropod antigen. Indeed, the greater optical densities shown in the $P$. papatasi ELISA could represent cross-reactivity of $P$. papatasi salivary antigens with some widespread antigen recognized by all four groups of sera.

Thorough evaluation of sand fly salivary components to the epidemiology or control of leishmaniasis will require large amounts of antigen, which is not feasible due to technical difficulties in rearing and dissecting sand flies. Until recently, only one salivary gland cDNA was cloned from $L$. longipalpis salivary glands, coding for the relatively small $(6.5 \mathrm{kDa})$ vasodilator maxadilan. ${ }^{10}$ More recently, ${ }^{13} 11$ new cDNA clones were identified, 9 of which encode secretory material as indicated by their leader sequences or isolation and amino-terminal sequence of their coded proteins. One such salivary gland cDNA, coding for the salivary anti-clotting protein was expressed in E. coli. Large amounts of product were obtained in inclusion bodies, which were further purified by HPLC to serve as an antigen in the present study. Reactivity to recombinant anti-clotting protein correlated positively with serum anti-Leishmania titers. However, it did not correlate with DTH response or with the response against total salivary homogenate, indicating that the response to individual salivary components may not be representative of that to the total homogenate. ${ }^{13}$

Immune reaction to salivary homogenate is complex, as indicated by the Western blot data (Figure 4). Each antigen in the homogenate may elicit a different pattern of response in different individuals, and may have a different temporal pattern of induced reactivity according to the timing and intensity of exposure. Ultimately, production and testing of several recombinant antigens may yield a mix that will substitute for the whole salivary homogenate. However, individual antigens may have unique value, as indicated by the recombinant anti-clotting protein. Serum anti-recombinant protein IgG levels correlated positively with serum IgG levels against leishmanial antigen, indicating that this recombinant antigen may be a good marker of vector exposure. Ultimately, before either saliva or recombinant antigens can be used for widespread ELISA screening, two controlled, basic studies should be accomplished: 1) the frequency with which exposed humans develop antibodies to those antigens will have to be determined; and 2) the specificity and sensitivity of an ELISA to detect those antibodies will have to be determined.

Acknowledgments: We are grateful to an anonymous reviewer for helpful criticism and suggestions. Work supported in part by grants from the Programa de Apoio aos Núcleos de Excelência (PRONEX, Brazil), and National Institutes of Health (TMRC, USA). Aldina Barral and Manoel Barral-Netto are Senior Investigators of the Brazilian National Research Council (CNPq).

Authors' addresses: Aldina Barral, Eduardo Honda and Manoel Barral-Netto, Centro de Pesquisas Gonçalo Moniz, FIOCRUZ, R. Waldemar Falcão, 121-Brotas, 40.295-001 SSA, Bahia, Brazil. Phone 55-(0)71-356.8782 Ext.215 FAX 55-(0)71-356.2255. E-mail: mbarral@cpqgm.fiocruz.br. Arlene Caldas and Jackson Costa, Departamento de Patologia, Universidade Federal do Maranhão, Praça Madre Deus No. 02, 65.025-560 São Luis, Maranhão, Brazil, Phone/ FAX 55-98-2225135. Vera Vinhas, Serviço de Imunologia, Hospital Universitário Professor Edgard Santos. Universidade Federal da Bahia, Rua João das Botas, s/n, 40.110-040 SSA, Bahia, Brazil, Phone 55-71-237-7353, FAX 55-71-245-7110. José M.C. Ribeiro, J.G. Valenzuela and Rosane Charlab, Section of Medical Entomology, Laboratory of Parasitic Diseases, National Institutes of Allergy and Infectious Diseases, Building 4 Rm. 126, 4 Center Dr. MSC-0425, Bethesda MD 20892-0425, Phone: (301) 496-3066 FAX: (301) 4024941. Edgar D. Rowton, Department of Entomology, Walter Reed Army Institute of Research, Washington, District of Columbia 20307, Phone: 202-782-0026.

Reprint requests: José M.C. Ribeiro, NIAID/LPD, Building 4 Rm. 126, 4 Center Drive, MSC-0425, Bethesda MD 20892-0425. Phone: (301) 496-3066. FAX: (301) 402-4941. E-mail: JRibeiro@nih.gov. 
REFERENCES

1. Killick-Kendrick R, 1979. Biology of Leishmania in phlebotomine sand flies. Lumsden W, Evans D, eds. Biology of the kinetoplastida. New York: Academic Press, 395-460.

2. Badaro R, Jones TC, Carvalho EM, Sampaio D, Barral A, Teixeira R, Johnson WD Jr, 1986. New perspectives on a subclinical form of visceral leishmaniasis. J Infec Dis 154: 10031011.

3. Cerf BJ, Jones TC, Badaro R, Sampaio D, Teixeira R, Johnson WD Jr, 1987. Malnutrition as a risk factor for severe visceral leishmaniasis in Northern Brazil. J Infec Dis 156: 1030-1033.

4. Badaro R, Jones TC, Lorenco R, Cerf BJ, Sampaio D, Carvalho EM, Rocha H, Teixeira R, Johnson WD Jr., 1986. A prospective study of visceral leishmaniasis in an endemic area of Brazil. J Infect Dis 154: 639-649.

5. Carvalho EM, Barral A, Pedral-Sampaio D, Barral-Netto M, Badaró R, Rocha H, Johnson WD Jr., 1992. Immunologic markers of clinical evolution in children recently infected with Leishmania donovani chagasi. J Infec Dis 165: 535-540.

6. Titus RG, Ribeiro JMC, 1990. The role of vector saliva in transmission of arthropod-borne diseases. Parasitol Today 6: 157160.

7. Titus RG, Ribeiro JMC, 1988. Salivary gland lysates of the sand fly Lutzomyia longipalpis enhance Leishmania infectivity. Science 239: 1306-1308.

8. Theodos CM, Ribeiro JMC, Titus RG, 1991. Analysis of enhancing effect of sand fly saliva on Leishmania infection in mice. Infec Immun 59: 1592-1598.

9. Belkaid Y, Kamhawi S, Modi G, Valenzuela J, Noben-Trauth N, Rowton E, Ribeiro J, Sacks DL, 1998. Development of a natural model of cutaneous leishmaniasis: powerful effects of vector saliva and saliva preexposure on the long-term outcome of Leishmania major infection in the mouse ear dermis. J Exp Med 188: 1941-1953.

10. Lerner EA, Shoemaker CB, 1992. Maxadilan: cloning and functional expression of the gene encoding this potent vasodilator peptide. J Biol Chem 267: 1062-1066.

11. Lerner EA, Ribeiro JMC, Nelson RJ, Lerner MR, 1991. Isolation of maxadilan, a potent vasodilatory peptide from the salivary glands of the sand fly Lutzomyia longipalpis. J Biol Chem 266: 11234-11236.

12. Soares MB, Titus RG, Shoemaker CB, David JR, Bozza M, 1998. The vasoactive peptide maxadilan from sand fly saliva inhibits TNF- alpha and induces IL- 6 by mouse macrophages through interaction with the pituitary adenylate cyclase-activating polypeptide (PACAP) receptor. J Immunol 160: 18111816.

13. Charlab R, Valenzuela JG, Rowton ED, Ribeiro JM, 1999. Toward an understanding of the biochemical and pharmacological complexity of the saliva of a hematophagous sand fly
Lutzomyia longipalpis. Proc Natl Acad Sci USA 96: 1515515160.

14. Jones LD, Hodgson E, Nuttal PA, 1989. Enhancement of virus transmission by tick salivary glands. J Gen Virology 70: 1895-1898.

15. Jones LD, Kaufman WR, Nuttal PA, 1992. Modification of the skin feeding site by tick saliva mediates virus transmission. Experientia 48: 779-782.

16. Bell JF, Stewart SJ, Wikel SK, 1979. Resistance to tick-borne Francisella tularensis by tick-sensitized rabbits: Allergic kendusity. Am J Trop Med Hyg 28: 876-880.

17. Feingold B, 1968. The allergic responses to insect bites. Ann Rev Entomol 13: 137.

18. Brummer-Korvenkontio H, Lappalainen P, Reunala T, Palosuo $\mathrm{T}, 1994$. Detection of mosquito saliva-specific IfE and IgG4 antibodies by immunoblotting. J All Clin Immunol 93: 551555.

19. Wikel SK, 1996. Host immunity to ticks. Ann Rev Entomol 41: $1-22$.

20. Schwartz BS, Ribeiro JMC, Goldstein MD, 1990. Anti-tick antibodies: an epidemiological tool in Lyme disease research. Am J Epidemiol 132: 58-66.

21. Schwartz BS, Ford DP, Childs JE, Thomas RJ, 1991. Anti-tick saliva antibody: a biologic marker of tick exposure that is a risk factor for Lyme disease seropositivity. Am J Epidemiol 134: 86-95.

22. Modi GB, Tesh RB, 1983. A simple technique for mass rearing Lutzomyia longipalpis and Phlebotomus papatasi (Diptera: Psychodidae) in the laboratory. J Med Entomol 20: 568-569.

23. Ribeiro JMC, Rowton E.D., Charlab R., 2000. Salivary amylase activity of the phlebotomine sand fly, Lutzomyia longipalpis. Insect Biochem Mol Biol 30: 271-277.

24. Badaro R RS, Barral A, Orge G, Jones TC, 1986. Evaluation of the micro enzyme-linked immunosorbent assay (ELISA) for antibodies in American visceral leishmaniasis: antigen selection for detection of infection-specific responses. Am J Trop Med Hyg 35: 72-78.

25. Reed S, Badaro R, Masur H, Carvalho E, Lorenco R, Lisboa A, Teixeira R, Johnson WJ, Jones T, 1986. Selection of a skin test antigen for American visceral leishmaniasis. Am J Trop Med Hyg 35: 79-85.

26. Sanders ML, Jaworski DC, Sanchez JL, DeFraites RF, Glass GE, Scott AL, Raha S, Ritchie BC, Needham GR, Schwartz BS 1998. Antibody to a cDNA-derived calreticulin protein from Amblyomma americanum as a biomarker of tick exposure in humans. Am J Trop Med Hyg 59: 279-285.

27. Sanders ML, Glass GE, Nadelman RB, Wormser GP, Scott AL Raha S, Ritchie BC, Jaworski DC, Schwartz BS, 1999. Antibody levels to recombinant tick calreticulin increase in humans after exposure to Ixodes scapularis (Say) and are correlated with tick engorgement indices. Am J Epidemiol 149: $777-784$. 